\title{
Designing Back Propagation Neural Network for Ship Seakeeping Investigations
}

\author{
Mohsen Khosravi Babadi, Hassan Ghassemi* \\ Department of Ocean Engineering, AmirKabir University of Technology, Tehran, Iran \\ *Corresponding author: gasemi@aut.ac.ir
}

Received January 07, 2014; Revised February 10, 2014; Accepted February 16, 2014

\begin{abstract}
In recent years, there has been more attention to predict the behavior of vessel in the sea (sea keeping). The more the deeps of vessel increases in the high speed and light vessels, the more calculations are necessary. In this paper, a BP (back propagation) neural network is presented that keeps sea keeping indexes under the categories of input and output of the network. Evaluation is based on a corvette model, and the stability parameter of wave has been evaluated by using MATLAB software. Comparison between the network output values and the expected values represent the amount of error, which is negligible, indicating that assessing the wave's stability values is possible via using (BP) back propagation neural network.
\end{abstract}

Keywords: sea-keeping analysis, back-propagation neural networks

Cite This Article: Mohsen Khosravi Babadi, and Hassan Ghassemi, "Designing Back Propagation Neural Network for Ship Seakeeping Investigations.” American Journal of Mechanical Engineering, vol. 2, no. 1 (2014): 21-27. doi: 10.12691/ajme-2-1-4.

\section{Introduction}

Proper operation of a vessel in calm water and turbulent conditions is defined as seakeeping operational capability. Optimizing this ability, either analytical or non-analytical, can lead to the development of operational conditions in preliminary steps of designing new vessels.

Nowadays, optimization of hull forms so as to develop a suitable tool has turned into an important branch in technical and engineering sciences. This branch of science is also used in marine and aerospace industries to optimize the proper movement behavior of hull forms, by means of potential flow solvers, RANS solvers or other validated solvers in comparison with experimental methods and the full scale model which presents reasonable results as well.

Optimization in vessel seakeeping ability has long been of engineers' interest in naval architecture. From this viewpoint, Grigoropoulos presented a method to optimize hull form considering hydrodynamic operation in calm and turbulent water. His method was based on initial optimization of the main hull form for better seakeeping function and the optimized hull results improved for the calm water resistance. He defined the effective parameters in vessel seakeeping operation such as ( $\left.\mathrm{C}_{\mathrm{p}}, \mathrm{LCB}\right)$, LCF, Cwp, $\mathrm{Kb}$ and $L$ and changed these parameters according to the original vessel hull form. Then, he studied the appropriate behavior of vessels in regular head-sea wave conditions by Hooke and Jeeves optimization algorithm and created optimized hull forms according to these parameters [7]. Kapsenberg attempted to find the optimized hull form with respect to seakeeping capability through a program based on linear strip theory and managed to improve it by Lewis form expressions for his desired hull. He used the program for designing a frigate vessel and presented the final hull form. This was implemented by investigation of three hull form parameters such as beam (B), draft and Sectional area such as functions of vessel length [8].

Sener et al. studied the effect of different parameters on high-speed vessel seakeeping capability. In their works, hull parameters were divided into two groups: main dimensions ( $\mathrm{L}, \mathrm{B}, \mathrm{T})$ and form parameters $\left(\mathrm{C}_{\mathrm{p}}, \mathrm{LCB}\right)$. In their studies, a parameter was assumed as constant in each group, and the next parameter was studied: for instance, in form parameters group, 225 hull forms, derived from the main hull form, were obtained to investigate the effects of $\mathrm{C}_{\mathrm{p}}$ and LCB on seakeeping ability. The 35 selected hull forms were studied and it was concluded that a decreasing in the vessel length results in a decrease in the heave amplitude but it increases the pitch amplitude. Decreasing $\mathrm{C}_{\mathrm{p}}$ will end in heave amplitude decrease as well.

However, commenting on the effect of $\mathrm{Cp}$ on pitch motion is impossible. Approaching LCB toward vessel aft also decreases heave amplitude but has no effect on pitch motion. It was also found out that changing the main dimensions of vessel is more effective than changing form parameters in heave amplitude [14].

Another study was conducted by Aranda et al. considering the constant speed of high-speed vessel in regular sine wave conditions. Their experimental and analytical results had a very good match in a vast domain of sea conditions. They studied heave, pitch, and roll dynamic motions in the encounter angles between 90 
degrees and 180 degrees. Their method was based on genetic algorithm and nonlinear optimization algorithm, and their initial data was obtained through system identification [9].

E. Sarioz calculated 2-D damping and added mass coefficients using Frank Close-Fit method, and by his method he could investigate effects of some geometrical and hull form coefficient on seakeeping criteria [5].

Combining of seakeeping related theories for ship design is done completely by Faltinsen and Svensen in 1990. Whole seakeeping theories for ships are introduced and strip theories, at least in preliminary design stage, are considered as the best and most practical method (by ignoring some limitations) for calculating ship motions in waves [11].

The most recent studies are carried out by Trincas et al. (2001), Alkan et al. (2003), Nabergoj et al. (2003), and Sayli et al. (2010) among which Trincas proposed an inverse problem solution of optimal hull forms and the others worked on the base of statistical analysis using a large amount of ship motion data related to various parameters in multi-linear models. [1]

Cepowski presented a method which makes it possible to determine optimum hull form of passenger car ferry with regard to selected sea-keeping qualities and added resistance in waves. In the first phase of investigations, a hull form characterized by the highest qualities was selected from the list of similar ships. Next, its optimum dimension ratios were determined. Design criteria were formulated by using a method based on deterministic scenarios, but objective functions of partial targets were determined in the form of artificial neural networks. For selection, the best design variant elements of fuzzy logic were used, which made it possible to show merits of the design by means of linguistic variables. Such approach made it possible to find the best hull form and its dimensions from the point of view of all considered criteria simultaneously [15].

In another paper, Cepowski presented the modeling of a car passenger ferry ship design parameters with respect to these design criteria such as sea-keeping qualities and additional resistance in waves. In the first part of the investigations, the approximations of selected statistical parameters of design criteria of ferry ship were elaborated with respect to ship design parameters. The approximation functions were obtained with the use of artificial neural networks. In the second part of the investigations, design solutions were searched for by applying the single and multi-criteria optimization methods. The multi-criteria optimization was performed by using Pareto method. Such approach made it possible to present solutions in such a form as to allow decision makers (ship owners, designers) to select the most favorable solutions in each individual case [16].

Tomasz Cepowski researched to elaborate design guidelines which could make it possible to improve seakeeping qualities of passenger-car ferries. The investigations for design guidelines were prepared in the form of regression functions as well as artificial neural networks on the basis of the results obtained from calculations with the use of numerical methods based on the theory of planar flow around a body [2].

David Winyall describes ongoing research to develop a flexible 3D hull form design process and modules with associated performance models, and integrate these modules into an existing ship synthesis model (SSM) in a multi-objective optimization approach to perform Naval Ship Concept and Requirements Exploration (C\&RE). Effectiveness is initially based on seakeeping indices and resistance, and then extended to a multi-objective genetic optimization of an Offshore Patrol Vessel (OPV) total ship design. Overall Measure of Effectiveness (OMOE) used in this process which is based on expert opinion and pair wise comparison. In this method cost and risk considered beside use of relatively simple and traditional parametric hull form model and design variables (LBP, B, $\mathrm{D}, \mathrm{T}, \mathrm{Cp}, \mathrm{Cx}, \mathrm{Crd}$ ) with performance based on parametric resistance algorithms (Holtrop 1984) and seakeeping indices (Bales 1980) [3].

One parameter or one variable cannot be used in order to evaluate and define seakeeping ability; rather a group of variables and parameters is required for evaluation. Here, eight parameters and variables, such as heave motion, pitch motion, relative speed, absolute acceleration and roll motion are considered.

The quality of a vessel seakeeping is defined as staying in the sea at all times. In sailing a vessel and all responses in the six states, it is assumed that the vessel does not lose its rigidity. Initial study of the vessel response in ideal long waves without considering the motion interactions is not correct due to the force distribution; motion-like heave generates pitch motion.

Increasing production of high speedvessels and demands for passenger's convenience are the most important reasons for researcher's interest in predicting the behavior of the vessels. First steps in order to take this important matter was harvested by Ursell (1949) and St. Denis and Pierson (St Denis and Pierson) in the twentieth century. Prediction of vessel behavior in the sea isrelatively morecomplex than the other ship's calculations. Therefore, its position in the design cycle, and comparisons were small in the past. Analyzing the behavior of the vessel at sea, followings have particular importance [17]:

- Predicting environmental conditions that the vessel situated

- Calculation of vessel behavior

- Set of criteria for evaluating vessel behavior at sea

Comparing different designs or evaluating a specific plan is dependent on the accuracy of the mentioned areas. Analyzing Vessel behavior at sea depends on the environment in which the vessel located and comparing criteria. These criteria in different vessels varies according to the vessel 's type. For example, evaluation criterion in a passenger vessel is increasing passenger's comfort while in a military one it's decreasing the helideck motions. Artificial neural network is a new information processing system based on the brain's structure. Discovering the activities of brain's nerve cells is the basis of the proposed mechanism. With smart features and capabilities of the human learning ability, these networks are expanding in two dimensions, in the first dimension of neural networks have taken steps in order to further coincidence with the capabilities of the human mind in recent years, and in the second dimension, the scope of their application is increasing. Developments are sensible in engineering evaluation domains in recent years [18]. This paper present what modeled in MATLAB software on ship's 
Sea keeping using an artificial back propagation (BP) neural network, in order to establish the evaluation of ship sea keeping. Neural network simulations as a recent development were founded before the advance of computers and experienced at least one major hurdle and several historical periods. Many important advances are obtained with a simple and inexpensive duplication and computer simulations. Following an initial period of enthusiasm and activity in this area, an era has passed with reluctance to these matters. The first artificial neuron was built in 1943 by a neurophysiologist Warren McCulloch and the logician Walter Pits. But the limitations of the technology at that time did not allow them to do more [15].

\section{Back-Propagation Neural Networks}

Figure 1 is a BP network structure:

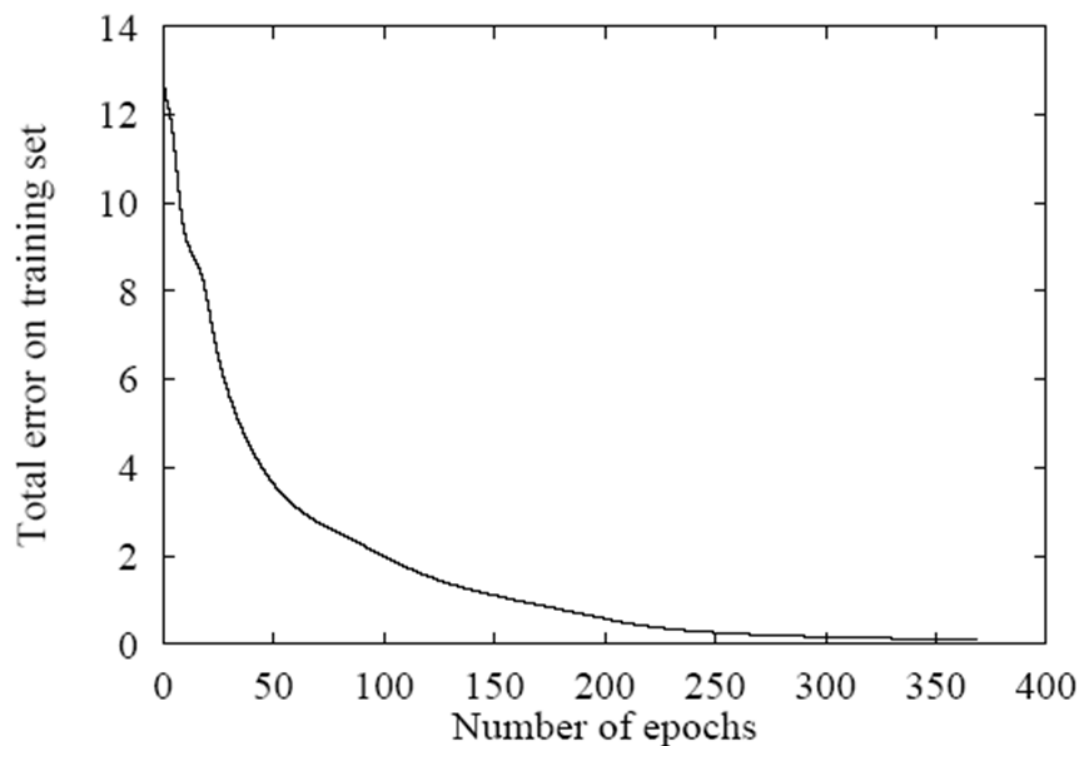

Figure 1. The structure of Back Propagation Neural Networks

The procedure of BP neural network learning algorithm, is as follows:

Step 0. Initialize weighting

Step 1. Create $n_{\text {in }}$ input nodes, $n_{\text {hidden }}$ hidden nodes and $n_{\text {out }}$ output nodes in the network

Step 2. Repeat steps 3 and 4 to reach the optimum condition (minimum fault)

Step 3. Release the example of $\mathrm{x}$ to forward on your network, for every $\mathrm{x}$ belonging to the training examples

Step 4. Move backwards Error $\mathrm{E}$ in the network.
BP algorithm is often repeated many times before the end. There are different conditions for termination of the algorithm, including:

- stop after a specified number of iterations

- Stop when the error is less than a specified value

- Stop when the error in the verification of examples coincides with specific pattern.

The method used in this paper is the second one. Figure 2 shows the training curve of this network resulted from BP algorithm.

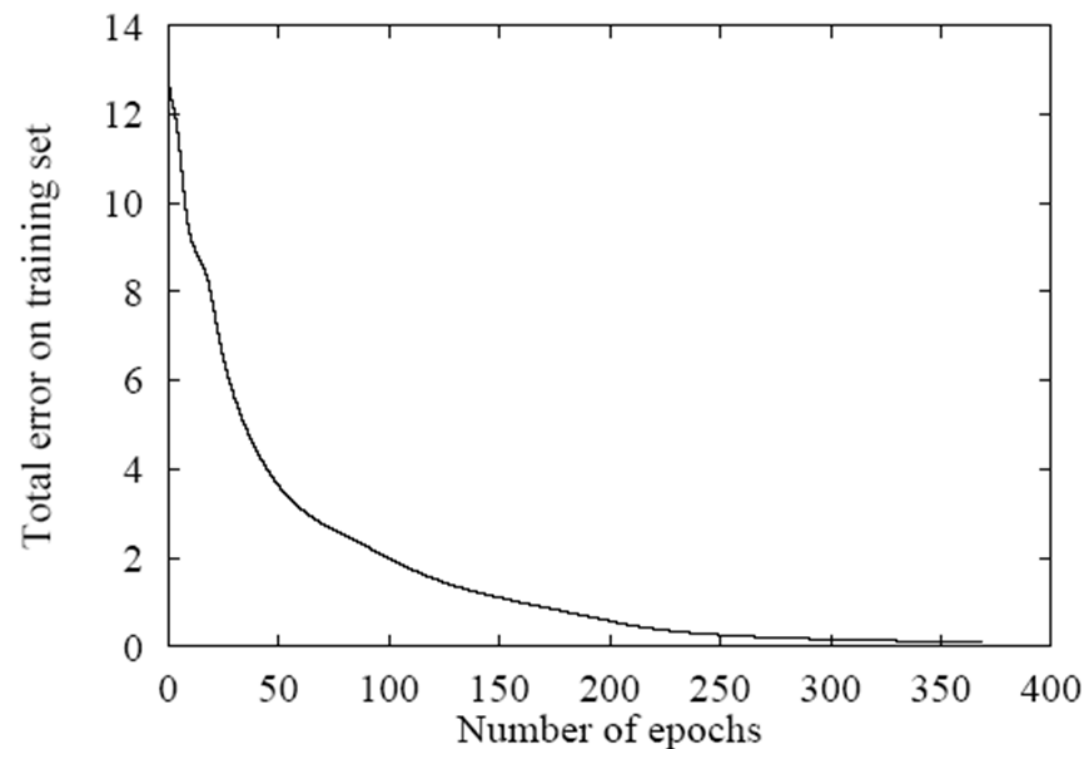

Figure 2. Learning Curve 


\section{Evaluation of Sea Keeping via (BP) Neural Network Model}

Selection of ship's sea keeping evaluation indexes has significant effect on navigation stability and also the other sea keeping factors. This paper analyzes the effect of the bad weather on the stability and safety of ship navigation via investigating various types of resources and researches, focusing on the ship navigations. Briefly, most important factors influencing sea keeping are roll, pitch, heave, reserved stability on the deck and MSI.

According to the criteria of ship's sea keeping, the following parameters are considered.

Table 1. Sea Keeping Evaluation Indexes

\begin{tabular}{cc}
\multicolumn{2}{c}{ Table 1. Sea Keeping Evaluation Indexes } \\
\hline Sea keeping factors & Evaluated Possible Values \\
\hline Roll & index value $15 \mathrm{~b}$ \\
Pitch & index value $5 \mathrm{~b}$ \\
Heave & index value $2 \mathrm{~m}$ \\
Deck Wetness & Probability 0.05 \\
Propeller Emergence & Probability of waste 0.05 \\
Slamming & Probability 0.03 \\
MSI & Index 0.4g (g=gravity) \\
\hline
\end{tabular}

Seven indexes of sea keeping presented in Table 1 are entered as the network's inputs in vector form. Ship's sea keeping amounts are obtained under irregular waves using spectral analysis and sea keeping relations.

Relationships proposed in this paper to calculate the density spectrum is based on ITTC function, in which the two parameters are calculated from population of sea wave spectrum, and then the ship behavior in irregular waves is predicted. ITTC's two parameter spectrums are suggested as below:

$$
S_{\xi}(\omega)=\frac{A}{\omega^{5 \exp }}\left\{-\frac{B}{\omega^{4}}\right\}
$$

Where $\mathrm{A}=173 h_{\gamma 3}^{2} / \mathrm{T}_{1}^{4} ; B=691 / \mathrm{T}_{1}^{4}, \quad \mathrm{~T}_{1}$ is concidered wave's week-period feature, $\omega$ is the wave frequency and $h_{1 / 3}^{-}$is acceptable wave height.

Statistical results show that the northern wind of Pacific Ocean can cause significant waves, including height $h_{1 / 3}^{-}=7 \mathrm{~m}$ and wave feature $T_{1}=8.7 \mathrm{~s}$. In order to calculate the North Pacific Ocean waves, when the wave height is $7 \mathrm{~m}$, results the curve illustrated in Figure 3.

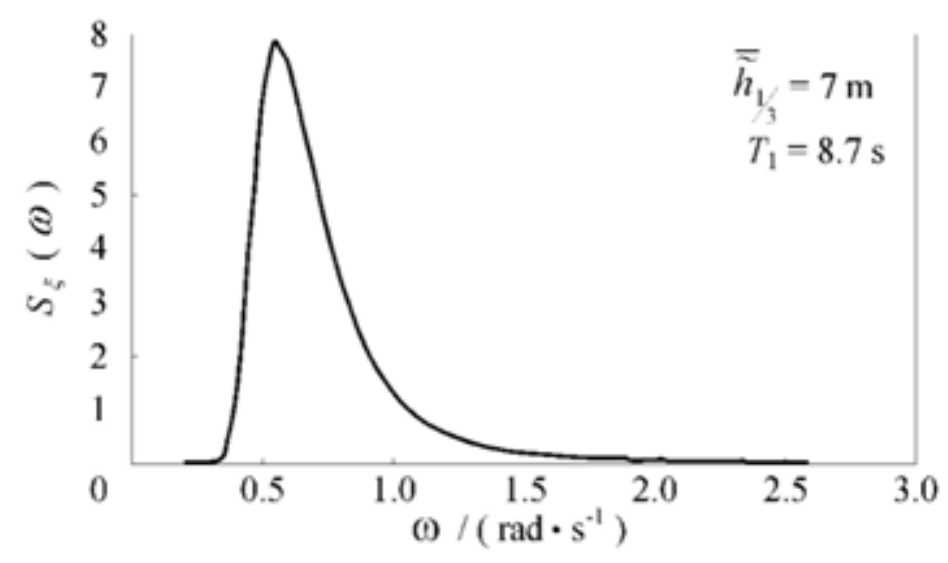

Figure 3. North Pacific Ocean waves when the wind creates significant wave height

Ship's motion in 6 degrees of freedom indicates linear motion of a ship at sea, which responds to the input for irregular waves, based on the irregular wave's theory and the spectral analysis of random process.

$$
\begin{gathered}
S_{0}\left(\omega_{e}\right)=\left|W_{\theta}\left(i \omega_{e}\right)\right|^{2} S_{\zeta}\left(\omega_{e}\right) \\
\omega_{e}=\omega-\frac{\omega^{2} v}{g} \cos \mu \\
S_{\zeta}\left(\omega_{e}\right)=S_{\zeta}(\omega) /\left(1-\frac{2 \omega}{g} v \cos \mu\right)
\end{gathered}
$$

Where, SF (X) is the Grad frequency spectrum for a random wave function; SF (Xe) is the function frequency of the encountered wave spectrum; $|\mathrm{WH}(\mathrm{iXe})|^{2}$ is the frequency response function for the motion of the ship; $\mathrm{SH}$ (Xe) is spectral function for the motion of the ship; X is frequency of the ship; Xe is encountering frequency; $v$ is velocity; $\mathrm{L}$ is wave direction and $\mathrm{g}$ is the acceleration due to gravity.
Thus, the variance of the ship's motion is 6 degrees of freedom.

$$
\sigma^{2}=\int_{0}^{\infty} S_{\theta}\left(\omega_{e}\right) d \omega_{e}=\int_{0}^{\infty}\left|W_{\theta} i \omega_{e}\right|^{2} S_{\zeta}\left(\omega_{e}\right) d \omega_{e}
$$

After computing the variance, all ship's sea keeping motion parameters, which are defined by random process theory, are obtained using statistical techniques.

Domain of roll is $\varphi_{\lambda 3} 2 \sqrt{m_{0}}$, where $m_{0}=\sigma^{2}=\int_{0}^{\infty} S_{\theta}\left(\omega_{e}\right) d \omega_{e}$, Assuming that the model ship is in tonnage of the $20000 \mathrm{~T}$ and height $170 \mathrm{~m}$, width of $25 \mathrm{~m}$ and a draft of $9.5 \mathrm{~m}$ and sailing in North Pacific ocean. Also wind index is 7 and the wave height indexes are $h_{1 / 3}^{-}=7 m, T_{1}=8.7 \mathrm{~s}$.

The roll sea keeping indexes in mentioned waves at different angles are shown in curve in Figure 4. Similar curves for pitch and heave are obtained from wave direction angular curves, using the same principles. 


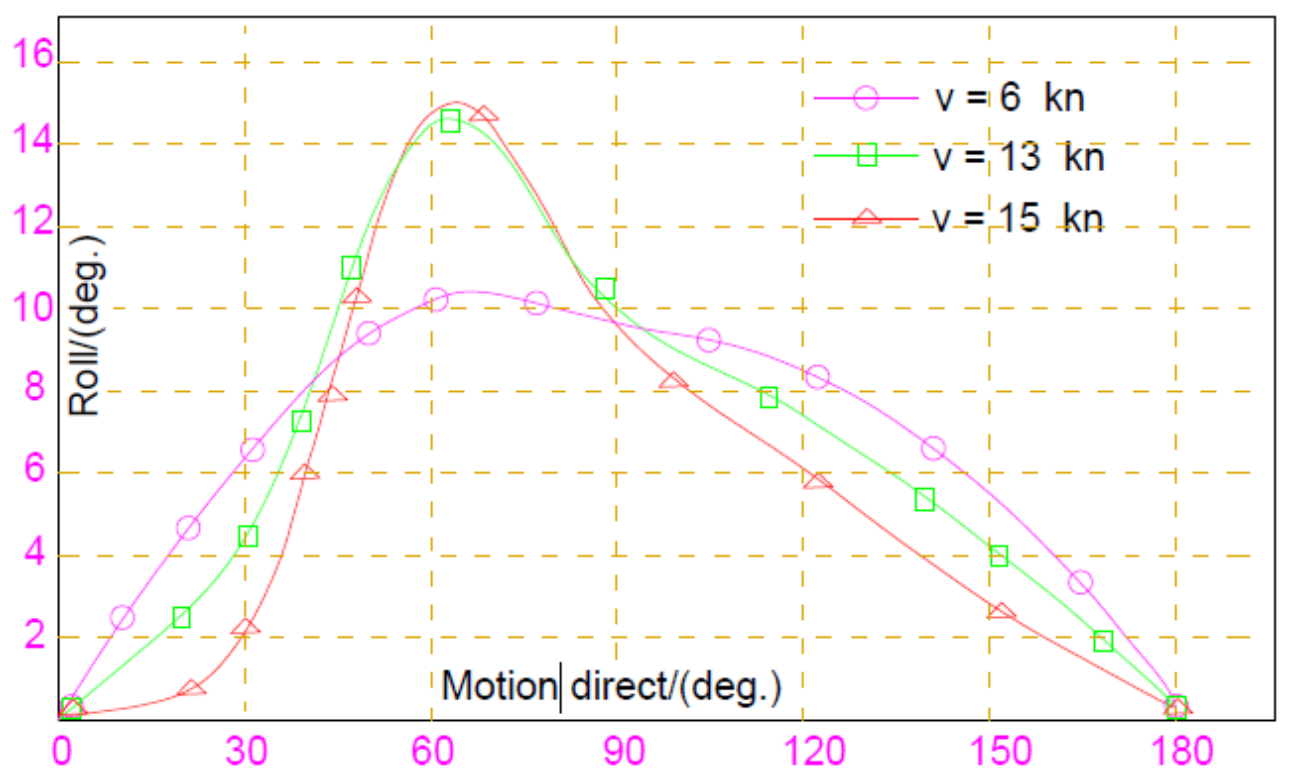

Figure 4. Significant wave height $h_{1 / 3}^{-}=7 m, T_{1}=8.7 \mathrm{~s}$. when rollingHave defined values with the wave direction angle curve

Other parameters introduced in table (1) includes: Slamming the bottom of the ship, Deck Wetness, Propeller Emergence calculated in accordance with irregular wave theory and slamming conditions, slamming the probability $\mathrm{P}$ and the unit time slamming number $\mathrm{N}$ can be calculated as:

$$
\begin{gathered}
p=e^{\left[-\left(\frac{d^{2}}{2 \delta^{2}}+\frac{v^{2}}{2 \delta^{2}}\right)\right]} \\
N=\frac{1}{2 \pi} \sqrt{\frac{\delta^{2}}{\sigma^{2}} p}
\end{gathered}
$$

Where $\mathrm{d}$ is the draft measure; $\sigma^{2}$ is variance of the relative displacement; $\mathrm{v}$ is critical relative velocity; $\sigma^{2}$ is to calculate the variance from their relative speed point of view.

In the Deck Wetness and Propeller Emergence theories wastes are under the irregularity.

\subsection{The Network Output Vector}

BP network output is given based on the comprehensive evaluation of ship's sea keeping. Output vector of this equation leads to a comprehensive analysis of the sea keeping.

$$
R_{X}=\sum_{n=1}^{n} K_{n}\left(1-\frac{p_{n}}{p_{n}^{\prime}}\right)
$$

Where, $R_{X}$ is certain condition of sea, course and speed of one ship for navigation in the conditions. $\mathrm{N}$ is the number of sea keeping factors. $K_{n}$ is actual weight; $p_{n}$ as the shipping conditions is calculated for each respond's domain or occurrence possibility and $p_{n}^{\prime}$ is the sea keeping's factor value of each index.

\subsection{Data Preprocessing for Back Propagation Neural Network Model}

In this paper, seven sea keeping factors were evaluated as network input, so the input vector to the Back propagation network has got 7 dimensions. Also the appointed equation is solved via this network output in order to overall evaluation of sample's sea keeping. Therefore the designed back propagation network output matrix has got same dimensions to the sample, which is designed for 30.28 of them are used as statistical to train the Bp (propagation) neural network and the remaining two samples are applied to test the modeled network.

The performance of data designed in this model, are part of examples, which are shown in Table 2.

Table 2. BP neural network model part sample data

\begin{tabular}{ccccccccc}
\hline No. & P1 & P2 & P3 & P4 & P5 & P6 & P7 & $\mathrm{R}_{\mathrm{x}}$ \\
\hline 1 & 0.00 & 2.70 & 1.85 & 0.09 & 0.10 & 0.08 & 0.20 & 0.3022 \\
2 & 4.50 & 2.10 & 1.30 & 0.05 & 0.02 & 0.02 & 0.05 & 0.5878 \\
3 & 14.65 & 1.00 & 0.35 & 0.08 & 0.07 & 0.04 & 0.09 & 0.3360 \\
4 & 11.50 & 2.34 & 1.35 & 0.07 & 0.03 & 0.04 & 0.06 & 0.3464 \\
5 & 7.90 & 3.10 & 1.70 & 0.09 & 0.05 & 0.05 & 0.21 & 0.2578 \\
6 & 5.45 & 3.90 & 1.80 & 0.10 & 0.10 & 0.06 & 0.26 & 0.1590 \\
7 & 0.00 & 2.30 & 1.50 & 0.06 & 0.05 & 0.08 & 0.16 & 0.4667 \\
8 & 0.80 & 1.35 & 0.09 & 0.10 & 0.05 & 0.04 & 0.03 & 0.6998 \\
9 & 2.80 & 1.50 & 1.00 & 1.10 & 0.05 & 0.04 & 0.03 & 0.5702 \\
10 & 8.45 & 2.70 & 1.50 & 0.08 & 0.04 & 0.05 & 0.20 & 0.1634 \\
\hline
\end{tabular}

Ship's sea keeping evaluation model using MATLAB software and the obtained network input and output vector from the sample data, leading to the selection of the network nodes which results applicable evaluation of ship's sea keeping. Stopping conditions of the training process from input to the output are setting the network systems to ensure the accuracy of different stability parameters. Using the MATLAB software, the navigation condition of a 20000T vessel at North Pacific Ocean, wind 7 , modeled and evaluated using back propagation network. The modeled network training process at mentioned evaluation is shown in Figure 5. 


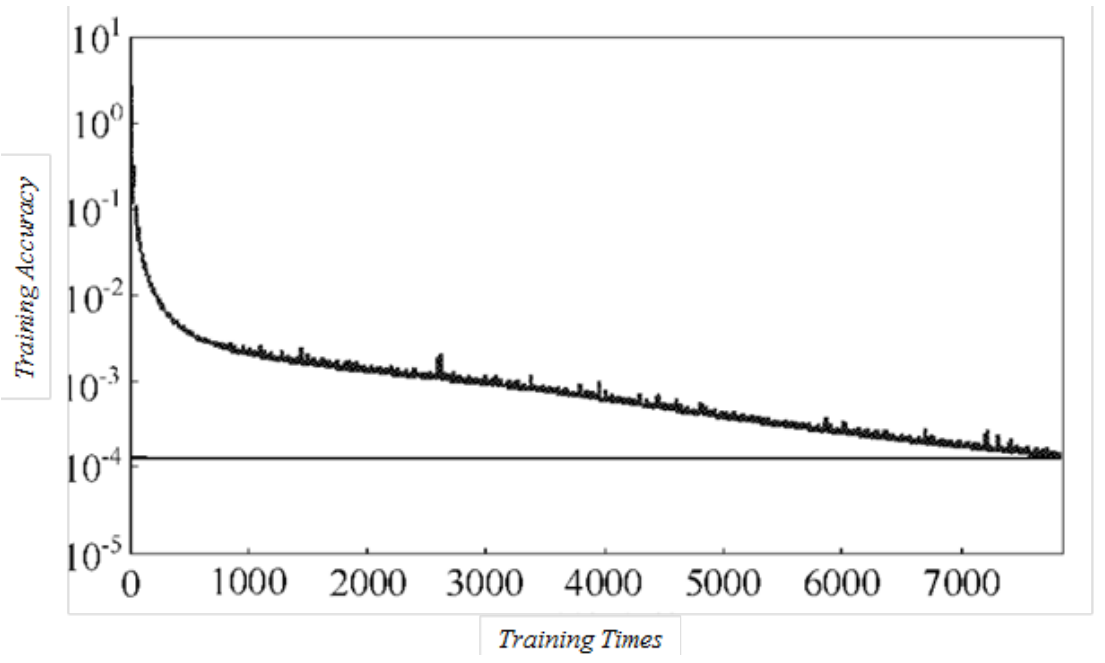

Figure 5. Network training process

Using the (Sim) command in MATLAB a function to train the neural network of back propagation is composed.

$$
\begin{gathered}
\mathrm{a}=\operatorname{sim}(\text { net, } \mathrm{P}-\text { test }) \\
\mathrm{a}=0.2994,0.1676
\end{gathered}
$$

Comparison and application of network output values, is leading to a comprehensive evaluation of thesea keeping parameters. Evaluation values obtained from the network and modeled relations are presented in Table 3.

Table 3. Network output value and the evaluated value of comparative evaluation equation

\begin{tabular}{ccc}
\hline Network output value & evaluation values & Absolute error \\
\hline 0.2994 & 0.3027 & 0.0033 \\
0.1676 & 0.1634 & 0.0042 \\
\hline
\end{tabular}

As shown in Table. 3 error of sea keeping evaluations are very small and results are acceptable. This indicates the possibility of using artificial networks to measure the wave resistance.

\section{Application Ship's Sea Keeping Evaluation in Sample Vessel}

The method proposed in this paper is used to evaluate sea keeping on a class of 2000T model in the ocean. Followings are obtained from inspection of the sample vessel:

170 meters long, 25 meters wide, 9.5 meters draft, 12.60 meters molded depth, $3621 \mathrm{~m}^{3}$ displacement, $235.60 \mathrm{~m}^{2}$ middle section area, $31331 \mathrm{~m}^{3}$ volume of drainage, ship navigating in the northern waters of Pacific Ocean, wind parameter7. The index of the wave height, 7 meters, the profile of periodic waves (period) is 8.7 seconds, the initial velocity of the ship $13 \mathrm{kn}$, angle of initial encountering $150^{\circ}$, the angle of the wave direction is $150^{\circ}$, values of 7 sea keeping factors respectively, 7.90 , $3.10,1.70,0.09,0.05,0.05,0.21$. There for the network input matrix is defined by:

$$
\mathrm{P} 1=[7.90 ; 3.10 ; 1.70 ; 0.09 ; 0.05 ; 0.05 ; 0.21]
$$

$\mathrm{P}$ matrix input to the modeled sea keeping network, gives the output, $\mathrm{a}=0.1742$. With varying the speed of ship and increasing it to the border of $15 \mathrm{knand}$ fixing the other parameters, sea keeping factor values will be $6.20,3.14$, 1.95, 0.10, 0.10, 0.07, and 0.27.

Thus the input network matrix $(\mathrm{P} 2)$ is defined as following:

$$
\mathrm{P} 2=[6.20 ; 3.14 ; 1.95 ; 0.10 ; 0.10 ; 0.07 ; 0.27]
$$

The output of the network model in this case would be $\mathrm{a}=0.3030$.

In the new case speed of ship will drop back to $13 \mathrm{kn}$ again. Encountering angle will be fixed and the angle of the wave will rise to $105^{\circ}$. In new situation, network model to evaluate sea keeping input is as follows:

$$
\mathrm{P} 4=[8.40 ; 1.15 ; 1.30 ; 0.06 ; 0.04 ; 0.04 ; 0.19]
$$

The output of the network is increased to $\mathrm{a}=0.3986$.

Table 4 for all cases, show the evaluation of sea keeping obtained from back propagation neural network.

Table 4. Aviation safety evaluation state value

\begin{tabular}{ccc}
\hline $\mathrm{P}(\mathrm{kn})$ & Course $\mathrm{P}(\mathrm{b})$ & Safety evaluation value \\
\hline 13 & 150 & 0.2698 \\
15 & 150 & 0.1742 \\
15 & 165 & 0.3030 \\
13 & 165 & 0.3986 \\
\hline
\end{tabular}

According to the evaluation made by the presented neural model, larger values make the border more secure in Table 4. Thus, referring to Table (0.4) and comparing the conditions listed, speed $13 \mathrm{kn} ; 165^{\circ}$ angle, has a more secure evaluation compared with three other state.

\section{Conclusions}

In this paper, a back propagation neural network (BP) designed and introduced and it has got the ability to assess ship's sea keeping. Applying presented method of modeling sea keeping behavior, more reasonable results are expected and it seems to be more economic either, and it shows that calculating model to model gives improved results. Using the neural network and MATLAB software for further investigation, proves that as a designing method for sea keeping evaluation is an effective method. 


\section{References}

[1] A. Sayli, A. Dursun A. and O. Ganiler, "Nonlinear meta- models for conceptual seakeeping design of fishing vessels, " Ocean Engineering, (2010).

[2] D. Peri, E.F. Campana, "High-fidelity models and multiobjective global optimization algorithms in simulation based design, " J. Ship Research, 49 (3), 159-175, (2005).

[3] D. Winyall, J. Edwards and A. Brown, " 3D Hullform Modeling to Support Naval Ship Design Synthesis and Multi-Objective Optimization,"International Ship Design Conference (ISDC), Glasgow, Scotland, (2012).

[4] E. Jahanbakhsh,R. Panahi and M. S., Seif,"Catamaran Motion Simulation Based on Moving Grid Technique,"Journal of Marine Science and Technology, Vol.17,No.2,pp.128-136, (2009).

[5] E. Sarioz, "Inverse Design of Ship Hullforms for Seakeeping," Ocean Engineering, vol. 36, pp. 1386-1395,( 2009).

[6] F. Alarrcin,U. Bugra Celebi,S. Ekinci and D. Ünsalan, "Neural Networks Based Analysis of Ship Roll Stabilization," 3rdInternational Conference on Maritime and Naval Science and Engineering, pp.217-220, (2010).

[7] G. J. Grigoropoulos, "Hull Form Optimization for Hydrodynamic Performance," Marine Technology, Vols. 41, No.4, pp. 167-182, (2004).

[8] G. K. Kapsenberg, "Finding the Hullform for Given Seakeeping Characteristics," MARIN, Wageningen, the Netherlands; IMAM, (2005).

[9] J. Aranda, R. Munoz, S. D. Canto, J. M. Díaz and D. S. Bencomo, "An Analysis of Modes Identification Methods for High Speed Crafts," Journal of Maritime Research, vol. 11, pp. 51-67, (2005).
[10] J. Hua, J.L., Wu and W.H. Wang," Effect of Asymmetric Hydrodynamic Impact on the Dynamic Response of a Plate Structure" Journal of Marine Science and Technology, Vol.8, No.2, pp.71-77, (2000).

[11] J. Journée and L. Adegeest, "Theoretical Manual of Strip Theory Program "SEAWAY for Windows"," Ship Hydromechanics Laboratory Delft University of Technology, Amarcon, (2003).

[12] M. R. Davis and D. S. Holloway, "The Influence of Hullform on the Motions of High-speed Vessels in Head Seas," Ocean Engineering, vol. 30, pp. 2091-2115, (2003).

[13] R. Dejhalla, Z. Mrsa and S. Vulkovic, "Application of Genetic Algorithm for Ship Hullform Optimization II," Ship build Program, vol. 48, pp. 117-133,( 2001).

[14] S. Ozum, B. Sener and H. Yilmaz, "A Parametric Study on Seakeeping Assessment of Fast Ships in Conceptual Design Stage," Ocean Engineering, vol. 38, pp. 1439-1447, (2011).

[15] T. Cepowski, "Determination of optimum hull form for passenger car ferry with regard to its sea-keeping qualities and additional resistance in waves, " Polish Maritime Research, 2(56) Vol 15, pp. 3-11, (2008).

[16] T. Cepowski, "On the modeling of car passenger ferryship design parameters with respect to selected sea-keeping qualities and additional resistance in waves, " Polish Maritime Research, 3(61) Vol 16, pp. 3-10, (2009).

[17] T. Szelangiewicz and T. Cepowski, "An Approach to Optimization of Ship Design Parameters with Accounting for Seakeeping Ability," Polish Maritime Research, (2002).

[18] W. J. Pierson and L. A. Moskowitz, "Proposed Spectral Form for Fully Developed Wind Seas Based on the Similarity Theory of S. A. Kitaigorodskii," Journal of Geophysical Research, vol. 69, pp. 5181-5190, (1964). 